\title{
Plasma rico en factores de crecimiento (PRGF) en la ortopedia, un camino hacia la ortobiología en México
}

\author{
Plasma rich in growth factors in orthopedics, a path to orthobiologics in Mexico
}

Rodolfo Sánchez Ayala, ${ }^{*}$ José Fernando Izquierdo Moncayo, ${ }^{\ddagger}$

Israel Gutiérrez-Mendoza, Álvaro Rodríguez Barrón," José Luis Carrillo Gamboa,"l

Montserrat García Balletbó, ** Ramón Cugat Bertomeuł‡

${ }^{*}$ Cirujano Ortopedista de la UNAM. Artroscopia, Ortopedia Regenerativa y Medicina Deportiva en Clínica del Pilar y Hospital Quirón, Barcelona, España. ISAKOS Teaching Center. Módulo de Ortopedia Regenerativa FEMECOT. Profesor Titular de Postgrado UNAM de la Especialidad de Ortopedia y adscrito al Módulo de Rescate Osteoarticular en el Hospital General «Dr. Miguel Silva» de Morelia, Michoacán. Hospital Memorial de Morelia, Morelia, México; ${ }^{\ddagger}$ Cirujano Ortopedista. Cirugía de Columna Vertebral. Intervencionismo Espinal. Ortopedia Regenerativa. Coordinador del Módulo de Ortopedia Regenerativa FEMECOT 2020-22. Hospital Ángeles Tijuana, Tijuana, México; §Cirujano Ortopedista. Maestría en Ciencias Médicas, Aguascalientes, México; "Maestro en Farmacología Básica adscrito a la Unidad de Investigación de Hospital General "Dr. Miguel Silva" de Morelia, Michoacán, México; "Cirujano Ortopedista de la UNAM. Director Fundador del Centro de Ortopedia Regenerativa en Querétaro. Cofundador del Capítulo de Ortopedia Regenerativas FEMECOT. Asesor Científico en Ortopedia de Regemat Bioimpresor 3D España, Profesor Titular del Curso «Ortopedia Regenerativa CORE», Querétaro, México; **Especialista en Anatomía Patológica, Máster en Traumatología del Deporte y Doctorado en Medicina por la Universidad de Barcelona, Unidad de Medicina Regenerativa del Hospital Quirónsalud, Fundación García Cugat, Instituto Cugat, Barcelona, España; \#‡irujano Ortopedista, Artroscopia, Medicina Deportiva y Doctorado por la Universidad de Barcelona. Mutualidad de Futbolistas, Federación Española de Fútbol, Delegación Cataluña, Fundación García Cugat, Instituto Cugat, Instituto Traumatología Hospital Quirónsalud, Barcelona, España.

\begin{abstract}
Resumen
El plasma rico en plaquetas (PRP) crea un medio para atraer células progenitoras, organizando la interacción de citoquinas y factores de crecimiento para estimular una curación natural así como la recuperación de la fuerza, movilidad y función normal del tejido lesionado. Existen revisiones sistemáticas y metaanálisis que sugieren que el PRP alivia el dolor en los pacientes con OA (osteoartritis) de rodilla por más de 12 meses, superior a cortisona y ácido hialurónico, así actualmente el PRP es considerado el tratamiento más recomendado para el manejo del dolor asociado a la OA de rodilla. Asimismo, se ha demostrado que es la herramienta más efectiva en el manejo conservador de la epicondilitis lateral, tendinopatía glútea y tendinopatía patelar. En tendinopatías del manguito rotador existen estudios nivel I a favor del PRP en cuanto a mejoría del dolor y de la función, de mayor rapidez de recuperación; sin embargo, la falta de evidencia de alta calidad ha limitado la aceptación y utilización generalizada. Las investigaciones recientes van a favor del PRP sobre los corticosteroides en el tratamiento conservador de la patología del manguito rotador. El PRP apunta firmemente como un potente analgésico y antiinflamatorio natural, además de tener potencial regenerador al actuar como señalizador en las células mesenquimales de nuestro organismo en el sitio que se esté aplicando. Esta herramienta debe estar ya en el arsenal de nuestra práctica diaria e ir dejando de lado el uso y sobreuso de infiltraciones con corticosteroides así como la administración de analgésicos, antiinflamatorios no esteroideos, sopesando el riesgo coste-beneficio.
\end{abstract}

Palabras clave: Plasma rico en factores de crecimiento, plasma rico en plaquetas, osteoartrosis, pérdida ósea, ortobiología, ortopedia regenerativa.

\section{Abstract}

PRP creates a path to attract progenitor cells, organizing the interaction of cytokines and growth factors to stimulate natural healing as well as improving strength, motion and normal function recovery of injured tissue. There are systematic reviews and meta-analysis that suggest that PRP relieves pain in patients with knee OA for more than 12 months. Superior to cortisone and hyaluronic acid, $P R P$ is considered the gold standard treatment for pain associated with knee OA. Likewise, it has been proven that it is the most effective tool for the conservative management of lateral epicondylitis, medial gluteal tendinopathy, and patellar tendinopathy. In

Correspondencia:

Rodolfo Sánchez Ayala

E-mail: mdms06@hotmail.com

Recibido: 18-05-2021. Aceptado: 02-06-2021.
Citar como: Sánchez AR, Izquierdo MJF, Gutiérrez-Mendoza I, Rodríguez BÁ, Carrillo GJL, García BM, et al. Plasma rico en factores de crecimiento (PRGF) en la ortopedia, un camino hacia la ortobiología en México. Orthotips. 2021; 17 (4): 222-236. https:// dx.doi.org/10.35366/102221 
rotator cuff tendinopathy there are level I studies that favor PRP regarding pain and function improvement, with a faster recovery time. However, the lack of high-quality evidence has limited the acceptance of its widespread use. Recent research favors PRP vS corticosteroids as the conservative treatment for rotator cuff disease. PRP firmly stands out as a powerful natural analgesic and anti-inflammatory in addition to having regenerative potential by acting as a signaler for mesenchymal cells of our own body in the site where is applied. This treatment should be already in our daily practice as another tool that would set aside the use and overuse of corticosteroid injections, as well as the administration of analgesics, non-steroidal anti-inflammatory drugs, pondering the risk-cost benefits.

Keywords: Plasma rich growth factors, platelet rich plasma, osteoarthrosis, bone loss, orthobiologics, regenerative orthopaedics.

\section{Introducción}

Para tratar las lesiones musculoesqueléticas se han utilizado antiinflamatorios no esteroideos (AINE) para bloquear la inflamación y aliviar el dolor en lesiones agudas y crónicas, sin importar la histopatología de la lesión, si hay un proceso inflamatorio o no. ${ }^{1}$ Las inyecciones de cortisona son efectivas a corto plazo en las tendinopatías, pero tienen efectos negativos a largo plazo y mayor tasa de recidiva en comparación con no aplicar corticosteroides. ${ }^{2}$ El plasma rico en plaquetas (PRP) tiene de dos a cuatro veces más que la concentración basal de plaquetas que va de 150,000 a $350,000 / \mu l^{3}$

Bansal y cols. refieren en un estudio que la aplicación de PRP con una cuantificación absoluta de $10,000,000,000$ de plaquetas en un volumen de $8 \mathrm{ml}$ provee un potencial significativo de condroprotección y mejora de la sintomatología comparada con el grupo control en OA de rodilla. ${ }^{4}$ Por lo anterior $1 \mu$ l equivale a $0.001 \mathrm{ml}$, asimismo $1,000 \mu \mathrm{l}$ a $1 \mathrm{ml}$, por lo cual en $10 \mathrm{ml}$ tendremos $10,000 \mu \mathrm{l}$. En el caso de un contaje de $800,000 / \mu \mathrm{l}$ de plaquetas ya centrifugadas en $10 \mathrm{ml}$ tendremos $8,000,000,000$ de plaquetas.
Los factores de crecimiento son proteínas dentro los gránulos alfa de las plaquetas como se muestran en la Tabla 1. Existe una correlación directa entre el número de plaquetas y la cantidad de factores de crecimiento: a mayor cantidad de plaquetas mayor cantidad de factores de crecimiento. ${ }^{8}$

EI PRP crea un medio favorable para atraer células progenitoras con el fin de organizar la interacción de citoquinas y factores de crecimiento para estimular una respuesta de curación natural así como la recuperación de la fuerza, movilidad y función normal del tejido lesionado. ${ }^{9}$

\section{Propiedades del plasma rico en plaquetas ${ }^{10,11}$}

Propiedades regenerativas: las plaquetas secretan diferentes factores de crecimiento: factor de crecimiento derivado de plaquetas (PDGF, por sus siglas en inglés), factor de crecimiento endotelial vascular (VEGF, por sus siglas en inglés), factor de crecimiento transformante $\beta$ (TGF- $\beta$, por sus siglas en inglés), factor de crecimiento fibroblástico (FGF, por sus siglas en inglés), factor derivado del estroma

Tabla 1: Características de los factores de crecimiento que se encuentran al interior las plaquetas. ${ }^{5-7}$

\begin{tabular}{cll}
\hline Siglas & Nombre & Características o propiedades \\
\hline 1 IGF-1 & Factor de crecimiento seudoinsulínico & $\begin{array}{l}\text { Regula la proliferación y la diferenciación celulares } \\
\text { Influye en la secreción de matriz por los osteoblastos y en la producción de } \\
\text { proteoglicanos, colágeno y otras proteínas no colágenas }\end{array}$ \\
TGF- $\beta$ & Factor de crecimiento transformado $\beta$ & Estimula la producción ce colágeno tipo I y III, angiogénesis reepitelización \\
VEGF & Factor de crecimiento vascular endotelial & Estimula la angiogénesis mediante regulación de la proliferación y la migración celular \\
PDGF & Factor de crecimiento derivado de las plaquetas & Estimula la proliferación, quimiotaxis, diferenciación celular y la angiogénesis \\
bFGF & Factor de crecimiento fibroblástico básico & Estimula la angiogénesis \\
& & Favorece la diferenciación de las células madre y la proliferación celular \\
EGF & Factor de crecimiento epidérmico & Favorece la producción de colágeno y la reparación tisular \\
& & Influye en la proliferación celular y citoprotección \\
& & Acelera la reepitelización \\
& Aumenta resistencia a la tracción en las heridas \\
& & Facilita la organización del tejido de granulación
\end{tabular}


Figura 1:

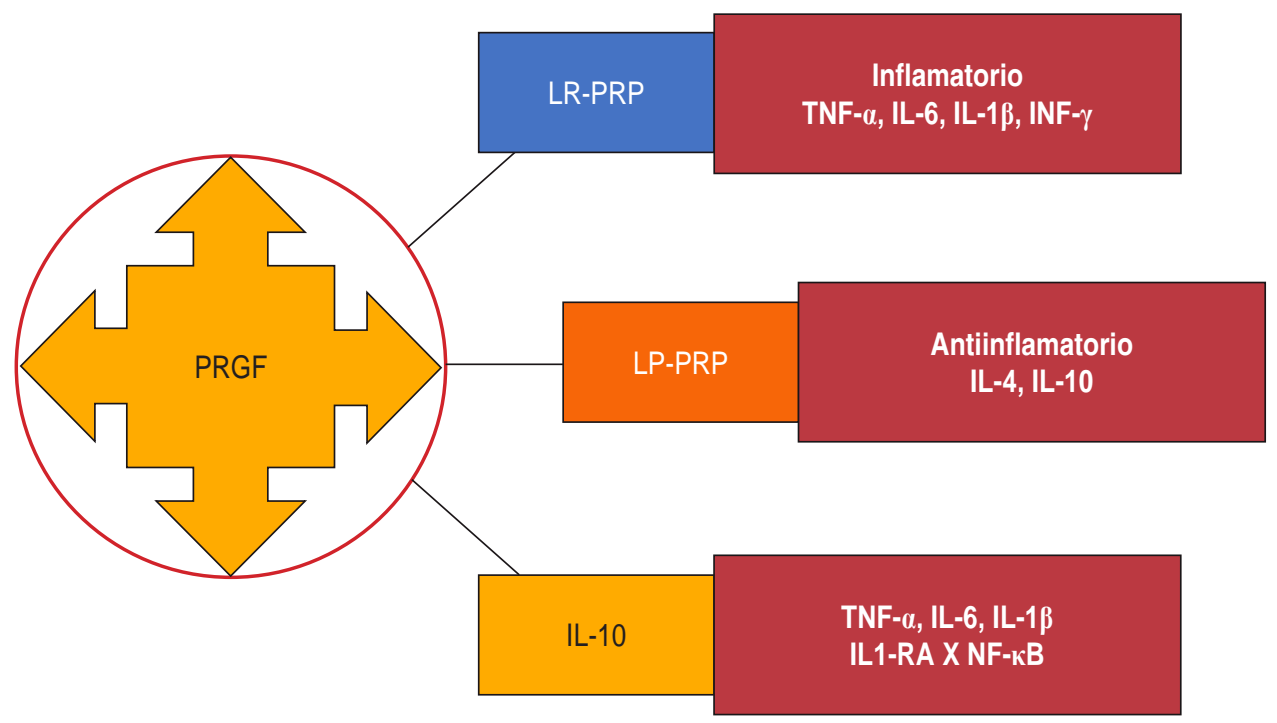

(SDF-1, por sus siglas en inglés), factor de crecimiento epidérmico (EGF, por sus siglas en inglés), promoviendo la movilidad, adhesión, proliferación, supervivencia, activación y diferenciación de las células madre mesenquimales. Activan la movilidad de las células madre mesenquimales (células señalizadoras) que se encuentran en la periferia de los vasos sanguíneos tanto en la médula ósea como en el tejido adiposo (o nichos periféricos previamente identificados).

Promoción de quimiotaxis: Formigli $L$ y cols. han apoyado la hipótesis de que los factores de crecimiento derivados de las plaquetas, algunos de ellos, tienen un efecto celular de homing, promueven la llegada de circulación incluyendo células multipotentes, que promueven la quimiotaxis de células madre endoteliales CD34++.

Efecto angiogénico: la neoangiogénesis sucede por medio de las células endoteliales y el reclutamiento de las células mesenquimales o señalizadoras que circulan. Las plaquetas son un requisito para la angiogénesis y la curación de tejido.

Efecto antimicrobiano: las plaquetas tienen un grupo de proteínas bactericidas conocidas como trombocidinas, las cuales están en los gránulos alfa, liberan otros péptidos antimicrobianos como el factor 4 plaquetario, RANTES, péptido 3 activador de tejido conectivo, proteína básica plaquetaria, timosina beta 4 y fibrinopéptidos $A$ y $B .{ }^{10}$

Efecto analgésico: tenemos receptores cannabinoides (CB) de tipo 1 y 2. Los CB1 se encuentran principalmente en el sistema nervioso central, a nivel

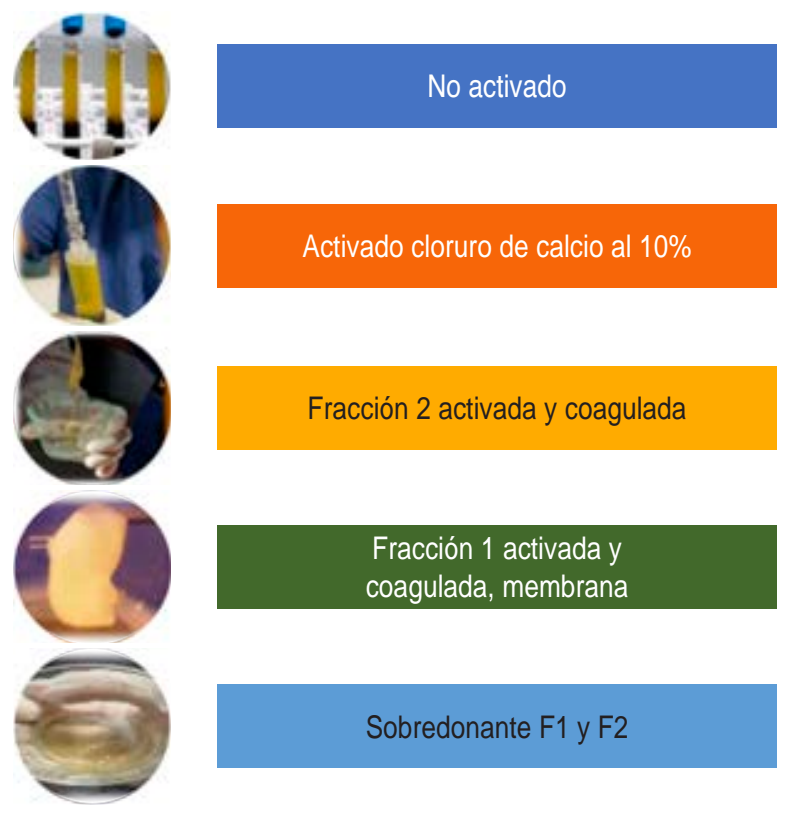

Figura 2: Las cinco formulaciones del plasma rico en factores de crecimiento. ${ }^{16}$

presináptico y postsináptico, con reducción en la liberación de ácido gamma-aminobutírico (GABA). Los CB2 se encuentran principalmente en células $T$ del sistema inmunológico, macrófagos y células $B$ y en las células hematopoyéticas, también en queratinocitos expresados en terminaciones nerviosas periféricas. Con el uso de PRP hay aumento de endocannabinoides como anandamida, 2-araquidonilglicerol, palmitoi- 
letanolamida, oleoyletanolamida, que actúan a nivel de los receptores CB1 y CB2 promoviendo la analgesia. ${ }^{11}$

Efecto antiinflamatorio: suprime el factor nuclear potenciador de las cadenas ligeras kappa de las células $B$ activadas, el cual tiene un papel importante en la respuesta inflamatoria, disminuye las citoquinas inflamatorias como la IL-6, IL-1 $\beta$, TNF- $\alpha$. Como antiinflamatorio aumenta la presencia de IL-4 y la IL-10 y esta última suprime el NF-kB por medio de la activación del receptor antagonista de la IL-1 (IL-1Ra). ${ }^{12}$ La Figura 1 muestra los elementos en los que actúa el plasma rico en factores de crecimiento (PRGF) durante el proceso de inflamación. ${ }^{12}$

\section{Procedimiento en la obtención de plasma rico en plaquetas}

Inicialmente se solicitan al paciente estudios de laboratorios como biometría hemática completa, tiempo de protombina y tiempo parcial de tromboplastina, química sanguínea 4 (glucosa, urea, creatinina, ácido úrico), perfil completo de lípidos.

La extracción de sangre se realiza en sala ambulatoria con cuatro horas de ayuno, y se recomienda tomar hasta 2 I de agua natural previos a la toma sanguínea para mejorar el volumen sanguíneo. La técnica de extracción dependerá del sistema a utilizar (abiertos o cerrados). Se extraen de 20 a $40 \mathrm{ml}$ de sangre venosa periférica, ésta se centrifuga a determinada velocidad dependiendo del kit utilizado, por ejemplo, el sistema de BTI PRGF- Endoret ${ }^{\circledR}$ requiere centrifugar a 1,800 RPM o $580 \mathrm{~g}$ durante ocho minutos. ${ }^{13}$

El PRP se divide en fracción 1 (F1), que corresponde al plasma pobre en plaquetas, el cual es el más superficial y la fracción 2 (F2), que corresponde al plasma rico en plaquetas, que se encuentra por debajo del plasma pobre en plaquetas y por encima de los leucocitos. Dependiendo de la lesión a tratar, se determina el volumen de PRP y las fracciones F1 y/o F2 que se administrarán. Por ejemplo, lo más frecuente es utilizarlo intraarticular en rodilla y el volumen que habitualmente se usa es de 8 a $12 \mathrm{ml}$, administrando las dos fracciones, independientemente de que sea rico o pobre, en factores de crecimiento, ya que finalmente se aprovechan todas las proteínas. En caso de lesiones tendinosas el volumen es de 1 a $5 \mathrm{ml}$, dependiendo del sitio y tamaño de la lesión, además de infiltrar la F2, puesto que tiene mayor cantidad de

Tabla 2: Descripción de las 5 formulaciones de plasma rico en factores de crecimiento de acuerdo al sitio y tiempo límite de aplicación. ${ }^{16}$

\begin{tabular}{|c|c|c|c|c|}
\hline Tipo & Formulación & Fracción & Ejemplo aplicación & Tiempo para aplicar \\
\hline 1 & No activado & $\begin{array}{l}\text { F1 (músculo), F2 (tendón, } \\
\text { ligamento), o F1 + F2. Se activa } \\
\text { con colágeno del organismo, } \\
\text { pero es menos potente y la } \\
\text { liberación de los factores de } \\
\text { crecimiento es más tardía }\end{array}$ & $\begin{array}{l}\text { En caso de no contar con } \\
\text { activador, infiltración en } \\
\text { tendón, ligamento músculo, } \\
\text { articulación, hueso }\end{array}$ & $\begin{array}{l}\text { No más de } 4 \text { horas, de lo con- } \\
\text { trario se considera contamina- } \\
\text { da la muestra }\end{array}$ \\
\hline 2 & $\begin{array}{l}\text { Activado con cloruro de calcio } \\
\text { a } 10 \% \text {, sin coagular }\end{array}$ & $\begin{array}{l}\text { Se puede utilizar F1 (músculo), } \\
\text { F2 (tendón, ligamento) o F1+F2 }\end{array}$ & $\begin{array}{l}\text { Infiltración de tendón, músculo, } \\
\text { articulación, úlceras en piel, } \\
\text { hueso }\end{array}$ & $\begin{array}{l}\text { Máximo entre los } 8 \text { a } 10 \\
\text { minutos de la activación }\end{array}$ \\
\hline 3 & $\begin{array}{l}\text { Fracción } 2 \text { activada } \\
\text { y coagulada }\end{array}$ & $\mathrm{F} 2$ & $\begin{array}{l}\text { Procedimientos quirúrgicos } \\
\text { abiertos como plastia de } \\
\text { tendón de Aquiles, supraespi- } \\
\text { noso, reparación ligamentaria } \\
\text { o en úlceras cutáneas. Se pue- } \\
\text { de combinar con injerto óseo } \\
\text { autólogo/aloinjerto }\end{array}$ & $\begin{array}{l}\text { El coágulo se forma entre los } \\
5 \text { a } 10 \text { minutos dependiendo } \\
\text { de la temperatura del quiró- } \\
\text { fano. A mayor temperatura } \\
\text { mayor rapidez de formación } \\
\text { del coágulo }\end{array}$ \\
\hline 4 & $\begin{array}{l}\text { Fracción } 1 \text { activada } \\
\text { y coagulada }\end{array}$ & $\mathrm{F} 1$ & $\begin{array}{l}\text { Fibrina tridimensional, formada } \\
\text { por sus proteínas contráctiles } \\
\text { trombotensina A y M. Membra- } \\
\text { na o malla como andamio con } \\
\text { chips de cartílago autólogo en } \\
\text { lesiones osteocondrales }\end{array}$ & $\begin{array}{l}30 \text { a } 50 \text { minutos, pero puede } \\
\text { ser antes si se mantiene a } \\
37^{\circ} \mathrm{C}\end{array}$ \\
\hline 5 & $\begin{array}{l}\text { Sobrenadante de la fracción } 1 \\
\text { y la fracción } 2\end{array}$ & $\mathrm{~F} 1+\mathrm{F} 2$ & $\begin{array}{l}\text { Alta concentración de células } \\
\text { señalizadoras }\end{array}$ & 60 minutos \\
\hline
\end{tabular}


TGF- $\beta 1$. En lesión muscular en cuanto al volumen va a depender del tamaño de la lesión y se aplica la F1, ya que es la que tiene menor cantidad de TGF- $\beta 1$, el cual se ha relacionado con formación de fibrosis. ${ }^{14,15}$ Existen diferentes formulaciones o combinaciones de plasma que poseen factores de crecimiento. La Figura 2 muestra las cinco principales formulaciones de plasma antes mencionadas, mientras que la $\mathrm{Ta}$ bla 2 las describe de acuerdo al sitio y tiempo límite de aplicación.

\section{Nueva clasificación de plasma rico en plaquetas ${ }^{17}$}

En una publicación reciente de expertos de opinión se ha propuesto una nueva clasificación de PRP que incluye seis categorías N1 a N6. ${ }^{17}$

Ejemplo para utilizar la clasificación propuesta por los expertos: se hace uso de N6, si el plasma es activado con cloruro de calcio a $10 \%$ se coloca el número 1, en caso contrario se usa 0 . La Figura 3 y la Tabla 3 muestran cómo utilizar la clasificación antes mencionada.

\section{Indicaciones y análisis de sus resultados}

\section{En pacientes con osteoartritis (OA)}

El hueso periarticular se divide en: placa de hueso subcondral, hueso trabecular subcondral y el hueso en los márgenes articulares. ${ }^{18}$

El hueso subcondral consiste en dos partes una placa cortical no porosa y pobremente vascularizada y el hueso subcondral que contiene médula ósea y hueso trabecular con vasos sanguíneos, nervios sensitivos, endotelio, osteoblastos, osteoclastos y médula ósea hematopoyética. ${ }^{19}$ La placa, el hueso subcondral y el cartílago articular forman la unidad funcional osteocondral, la cual está bajo estrés mecánico que desencadena respuestas celulares adaptativas y establece una comunicación entre ellas. ${ }^{19,20}$ El hueso subcondral atenúa la carga articular de 30-50\% y aporta a la capa más profunda del cartílago articular nutrientes y elimina los productos de desecho. ${ }^{21,22}$ La obstrucción del flujo venoso en el hueso provoca una hipertensión intraósea, disminuye la perfusión e hipoxia. La hipoxia estimula la angiogénesis y esto tiene un rol importante en la comunicación con el cartílago articular en OA. La neovascularización y otros canales a través del cartílago calcificado y la placa subcondral, así como la difusión a través del sistema lacunocanalicular y la matriz ósea, pueden facilitar el tránsito de las citoquinas derivadas de los osteoblastos, lo que puede contribuir a la degeneración del cartílago. ${ }^{23}$

EI PRP en hueso subcondral y en cartílago: aumenta la presencia de las células madre mesenquimales y condrocitos, promueve la autofagia celular, incrementa la presencia de proteoglicanos, colágeno tipo II, IL-4 e IL-10 y activa los cannabinoides endógenos CB1 y CB2. El PRP disminuye las citoquinas proinflamatorias, IL-6, IL-1 $\beta$, TNF- $\beta$, MMP3 MMP13, ADAMTS-5, ciclooxigenasa-2 (COX-2), apoptosis. ${ }^{24}$

EI PRP tanto intraarticular como intraóseo aumenta la síntesis de ácido hialurónico y lubricidina por medio de los sinoviocitos y condrocitos, tiene un efecto condrogénico por medio de señales celulares con las células mesenquimales a nivel del hueso sub-

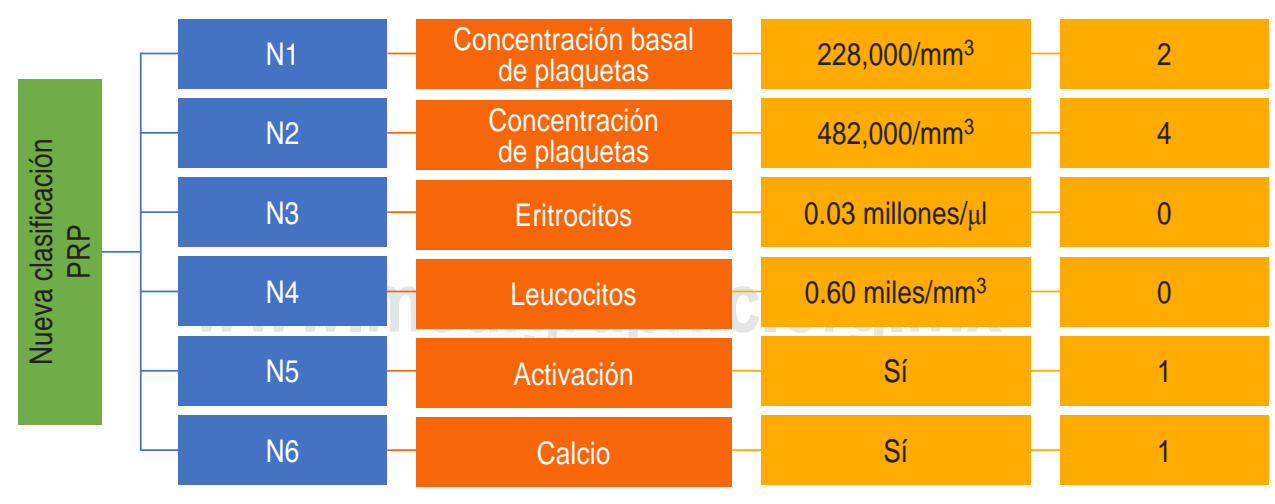

Figura 3: Nueva clasificación de plasma rico en plaquetas (PRP), de acuerdo con la concentración basal de plaquetas, concentración plaquetaria después de la centrifugación, si hay presencia o no de eritrocitos o de leucocitos, si es activado o no con cloruro de calcio a $10 \%$ o con otro activador. ${ }^{17}$ 
Tabla 3: Nueva clasificación de plasma rico en plaquetas en opinión de expertos recientes. ${ }^{17}$

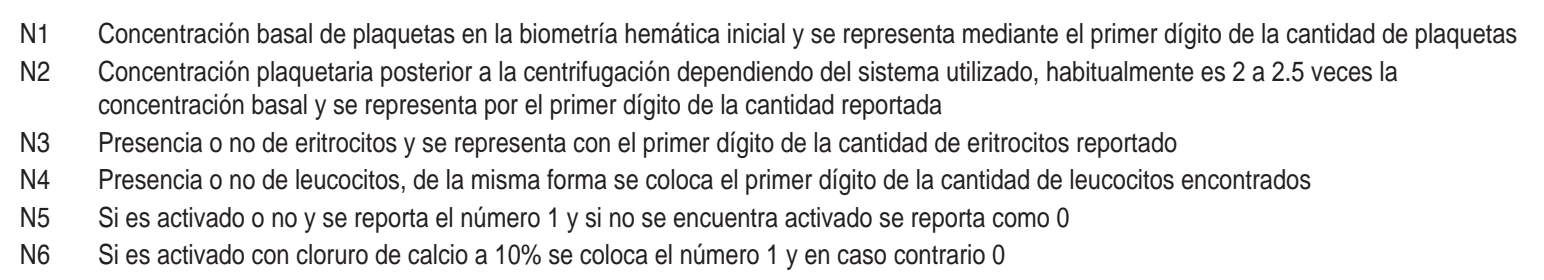

condral, además suprime el NF-кB disminuyendo las citoquinas inflamatorias, generando una homeostasis en el líquido sinovial. ${ }^{25}$ EI PRP intraóseo: actúa a nivel de la membrana sinovial y el hueso subcondral, en éste disminuye la sobreexpresión de TGF $\beta$ que habitualmente altera las células mesenquimales, evitando así la senescencia de las mismas. ${ }^{26}$

En la Figura 4 están los principales metaanálisis en el tratamiento de OA de rodilla y cadera con PRP en forma intraarticular en comparación con tratamientos convencionales. En cuanto al protocolo de tratamiento establecido son tres sesiones, una sesión cada dos semanas, se realiza la preparación del PRP en una sala ambulatoria, con el kit de preparación que corresponda a sistema abierto o cerrado, se activa con cloruro de calcio a 10\%, previa asepsia y antisepsia de la rodilla se infiltran de 8 a $12 \mathrm{ml}$ de PRP y/o de PRP y plasma pobre en plaquetas (PPP) según sea el volumen obtenido. ${ }^{27,28}$ Cuando es intraóseo en rodillas se infiltran en la primera sesión $4 \mathrm{ml}$ en cada cóndilo femoral y en cada meseta tibial bajo sedación con control fluoroscópico con un trócar de 11, 13 o 15 $\mathrm{G}$; e intraarticular con un volumen de 8 a $12 \mathrm{ml}$ con aguja 21 o 22 Gauge. Posteriormente se realizan dos sesiones de PRP intraarticular cada dos semanas. ${ }^{29}$

En lesiones osteocondrales de 2 o más $\mathrm{cm}^{2}$ Cugat y cols. proponen el tratamiento realizando una revisión artroscópica para: delimitar la lesión, realizar la escarificación de ella, realizar microfracturas si precisa, y rescatar restos de cartílago sano de la misma lesión o alrededor de ella. Con los restos de cartílago y la F1 del PRGF obtienen una malla que se coloca, vía miniartrotomía, en el lugar de la lesión, haciendo un andamio/injerto biológico con cartílago autólogo sano en el defecto osteocondral. ${ }^{30,31}$

Ip y colaboradores en un estudio sobre la eficacia y seguridad de las inyecciones de PRP y células mesenquimales (MSC), una revisión de la literatura, en el análisis de 30 artículos en PubMed concluyen que las infiltraciones tanto con PRP y MSC son efectivas en pacientes con leve a moderada $\mathrm{OA}$, dando un alivio sintomático, restableciendo la función y mejorando el potencial de reparación del tejido de las articulaciones afectadas. EI PRP trabaja mejor en OA grado I-II y las MSC mejor en OA grado III-IV. Los tratamientos repetitivos y con grandes volúmenes aplicados dan mejores resultados clínicos en ambos tratamientos, además sin efectos adversos significativos. ${ }^{32}$ Dwyer y Chahal comentan que las infiltraciones en la OA de rodilla han sido el centro de investigación significativa en las últimas décadas; revisiones sistemáticas y metaanálisis sugieren que el PRP puede aliviar el dolor de los pacientes durante más de 12 meses, siendo su efectividad superior a la cortisona y al ácido hialurónico. En cuanto al concentrado de aspirado de médula ósea (BMAC, por sus siglas en inglés), aún no se aprueba su eficacia, y la toma es más difícil de hacer que una toma de la vena periférica, como lo es en el caso del PRP. Las investigaciones en el uso de células madre mesenquimales expandidas autólogas y alogénicas continúan y muestran un futuro prometedor. Hasta hoy el PRP permanece como el estándar de oro para el tratamiento del dolor asociado a la OA de rodilla. ${ }^{33}$

Debido a la eficacia del PRP, el aspirado de médula ósea (BMA, por sus siglas en inglés) y el BMAC que han generado resultados optimistas, se ha propuesto la combinación de estos productos biológicos. Los macrófagos se encuentran en la médula ósea, tienen plasticidad y pueden cambiar los fenotipos desde el subtipo M1 a M2 para disminuir la inflamación crónica. La combinación de PRP y BMAC se parece a la cascada natural que ocurre en la curación de un hueso fracturado. Hay aumento de los neutrófilos en el hematoma de la fractura, éstos son reemplazados por macrófagos, después cambian a macrófagos M2 y reclutan selectivamente linfocitos. Los macrófagos M2 secretan altos niveles de citoquinas antiinflamatorias y factores fibrogénicos y angiogénicos, ya que sirven para resolver la inflamación y estimular la regeneración tisular y el tejido de granulación se 
forma mediante la fibrinolisis del hematoma de la fractura. La degradación de la fibrina atrae y facilita la invasión, proliferación y diferenciación de las MSC en el área lesionada.

La evidencia demuestra que los perfiles de los factores de crecimiento, citoquinas y quimiocinas vistos en el PRP y BMAC son diferentes y trabajan mejor de una manera conjunta. Es masiva la evidencia científica que apoya al PRP como un ortobiológico. La adición del PRP a BMAC provee un medio natural de cultivo a las MSC localizadas en la periferia y en médula ósea. ${ }^{34}$

Caplan menciona que es más apropiado llamar a las células madre mesenquimales como células de señalización medicinal, ya que responden in vivo a una lesión secretando factores bioactivos que tienen un factor inmunomodulador, proporcionando opciones terapéuticas prometedoras. Según consenso en la opinión de los expertos, el término "célula madre» se ha empleado en exceso. Se recomienda que el uso de productos celulares mínimamente manipulados y que células expandidas por cultivo derivadas de tejidos se denominen «terapia celular», y la naturaleza de estos tratamientos debe entenderse de manera puntual. ${ }^{35}$

La terapia con MSC regula la inflamación y tiene efecto analgésico. Pocos estudios muestran datos clínicos prometedores a largo plazo para lesiones articulares. EI BMAC tiene células progenitoras y factores de crecimiento con propiedades reparadoras autodirigidas y tróficas que hacen que migren hacia áreas de daño, ya en el sitio de lesión liberan citoquinas y factores de crecimiento que inducen la actividad paracrina y autocrina, ayudando al proceso de cicatrización y modulación de la inflamación. Los tejidos extraarticulares cicatrizan siguiendo una secuencia predefinida de eventos, una extravasación de sangre, forman un coágulo primario de fibrinaplaquetas y llenan el espacio entre los extremos del tejido lesionado, creando un andamio para que las células migren y remodelen el coágulo primario, formando una cicatriz que llena el defecto. En los tejidos intraarticulares (cartílago, ligamento y meniscos) se activan los sinoviocitos y aumentan la expresión del activador de plasminógeno, que se secreta de forma intraarticular, ya que en el líquido sinovial se convierte en plasmina, que degrada la fibrina y ésta es incapaz de formar un coágulo estable. La pérdida temprana de este andamio provisional se considera una de las razones por la cual los tejidos dentro de las articulaciones no cicatrizan fácilmente. ${ }^{35}$

Laver y cols. revisaron todos los estudios que evaluaron el tratamiento con PRP para el tratamiento de la patología degenerativa de cartílago. Un total de 29 estudios fueron incluidos, de estos nueve fueron prospectivos aleatorizados y todos reportaron mejoría de los síntomas con PRP al final de 12 meses de seguimiento, siete de los cuales tuvieron resultados superiores de manera significativa, en pacientes jóvenes y con cambios tempranos de OA. ${ }^{36}$ Estrada y cols. comparan infiltraciones con PRP, BMA y células mesenquimales derivadas de tejido adiposo en $O A$

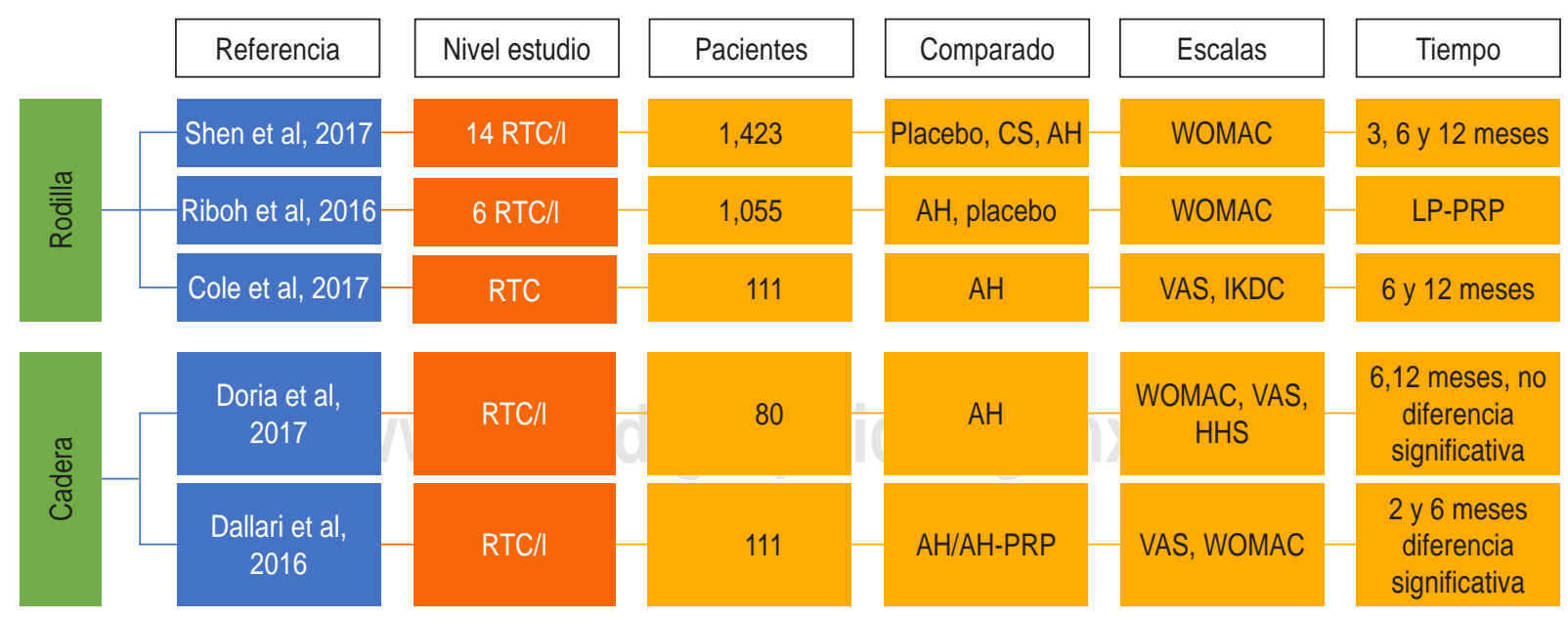

Figura 4: Metaanálisis de evaluación de diferentes tratamientos con plasma rico en plaquetas (PRP) en gonartrosis y coxartrosis. RTC= estudios aleatorizados controlados; $\mathrm{CS}$ = corticosteroides; $\mathrm{AH}$ = ácido hialurónico, WOMAC = índice de osteoartritis de las Universidades Western Ontario y McMaster, VAS = escala visual analógica, IKDC = Comité Internacional de Documentación sobre la Rodilla, HHS = escala de cadera de Harris. ${ }^{12}$ 
sintomática, donde se estudiaron a 89 pacientes, divididos en tres grupos de tratamiento, en todos se valoraron tres escalas: IKDC (International Knee Documentation Committee), Knee Score, Function Knee Score durante 265 días, mejorando de manera significativa a los 90 días de tratamiento. La literatura actual apoya el uso de PRP en OA temprana y preferentemente en jóvenes. El PRP es el tratamiento que requiere menos recursos de los tres, sobre todo porque no requiere hospitalización y los otros dos tratamientos requieren hospitalización y son más caros. En conclusión, los tres tratamientos demostraron que pueden ser efectivos, seguros y baratos en el manejo de la OA sintomática. ${ }^{37}$

La osteocoreplastia se ha descrito como el abordaje mínimo invasivo para lesiones focales del hueso subcondral que se observan en la resonancia magnética nuclear, detectándose una alteración de la intensidad de señal, lo anterior corresponde a edema óseo, necrosis trabecular, quistes, fibrosis y fragmentos de cartílago. Comúnmente se utiliza el término "señal de edema de la médula ósea», sobre todo en T2 ponderada. Lo anterior se puede relacionar con una rápida degeneración de la articulación y mayor dolor. Una intensa investigación está enfocada al uso de biológicos para ayudar a mantener y mejorar la salud del cartílago. La osteocoreplastia es un procedimiento mínimamente invasivo para tratar las patologías y prevenir la progresión hacia la OA. Las principales indicaciones son edema de médula ósea con dolor y una asociación a quistes subcondrales asociados a OA. Durante el procedimiento se inyecta médula ósea de alta calidad y pequeños cilindros de hueso autólogo en el área afectada bajo control fluoroscópico para llenar el espacio intertrabecular, además de mejorar la remodelación ósea. ${ }^{38}$

Raeissadat y cols. realizaron un estudio aleatorizado a un año, comparando los efectos de la inyección intraarticular del PRP, ácido hialurónico y ozono en la OA de rodilla en 200 pacientes. Todos los grupos a los dos meses tuvieron una mejoría significativa del dolor, rigidez y la función. En cuanto al ozono tuvo mejores resultados a corto plazo, es decir, a los dos meses de seguimiento; sin embargo, el PRP y el PRGF mejoraron a largo plazo la sintomatología de la OA de rodilla hasta 12 meses. ${ }^{39}$

En otro estudio se evaluaron 50 pacientes con dos dosis semanales de un total de 20 sesiones de infiltraciones con ozono en rodilla, mejorando la escala visual analógica (VAS, por sus siglas en inglés) e ín- dice de osteoartritis de las Universidades de Western Ontario y McMaster (WOMAC, por sus siglas en inglés). El ozono tiene propiedades analgésicas, elimina productos de degradación y es fluidificante del líquido sinovial, es un modulador de la inflamación, actúa en las prostaglandinas y las peroxidasas, estimula la circulación y la oxigenación del tejido, activa el metabolismo, mejora la nutrición del cartílago, aliviando el dolor y la función de la rodilla. ${ }^{40}$

Una revisión sistemática de estudios aleatorizados de la ozonoterapia en OA de rodilla evaluó 11 estudios, incluyendo 858 pacientes. Se compararon con placebo, ácido hialurónico (AH), AH y PRP, corticosteroides, dextrosa hipertónica, radiofrecuencia o celecoxib más glucosamina. Se encontró que ningún estudio fue de buena calidad. No se reportaron complicaciones serias, se logró alivio del dolor y la funcionalidad a corto y mediano plazo. Por tanto, no hay una clara indicación para comparar la ozonoterapia con otros tratamientos establecidos para la OA de rodilla. ${ }^{41}$

\section{Epicondilitis lateral}

El tratamiento se realiza bajo control de ultrasonido en el tendón extensor de mano y muñeca, que involucra el extensor corto del carpo radial, extensor común de los dedos y el extensor cubital del carpo, de la misma manera de tres sesiones, una cada dos semanas. Mishra y cols. tienen un estudio a doble ciego multicéntrico prospectivo aleatorizado, nivel 2, con 230 pacientes, a las 24 semanas se observa una mejoría del dolor en $71.5 \%$ contra el control (anestésico) con una tasa de éxito de $82.1 \%$.

Hay 29 estudios, de los cuales 18 son aleatorizados, en los cuales es superior el PRP contra corticosteroides y anestésico. ${ }^{42}$ También hay un metaanálisis nivel 1, que analiza 16 estudios aleatorizados observando la eficacia de las inyecciones en tendinopatías: el PRP mejora el dolor contra el control. ${ }^{43}$

La mayoría de las investigaciones en el tratamiento con PRP en epicondilitis lateral han demostrado en revisiones sistemáticas que tienen un mejor, aunque tardío, efecto terapéutico comparado con la infiltración con corticosteroides hasta dos años postinfiltración. En la revisión realizada por Collins y cols. los estudios aleatorizados que demostraron una mejoría significativa comparada con corticosteroides fueron los que utilizaron PRP rico en leucocitos. ${ }^{36}$

En epicondilitis crónica la inyección de PRP mejora de manera uniforme y prolongada el dolor y la función, significativamente más que la inyección 
local de anestésico (nivel II de EC) o la de corticoides (nivel I de EC). ${ }^{44}$

\section{Tendinopatía del glúteo medio}

Se realiza bajo control de ultrasonido a nivel de la inserción del glúteo medio en trocánter mayor, de la misma manera, tres sesiones una cada dos semanas. Estudio nivel II, doble ciego aleatorizado con dos años de seguimiento, en 80 pacientes con tendinopatía glútea crónica, se mejoró la función y el dolor comparando LR-PRP contra infiltración con corticosteroides, manteniéndose la mejoría con LRPRP hasta 24 meses contra corticosteroides que tan solo duró seis meses. ${ }^{45}$

\section{Reconstrucción ósea (pérdidas óseas, auto/aloinjerto, técnica Masquelet)}

EI PRP también se utiliza en reconstrucción ósea combinándose con injerto óseo autólogo de cresta iliaca, aloinjerto en chips óseos de esponjosa, concentrado o sólo aspirado de médula ósea, matriz ósea desmineralizada o incluso proteína morfogenética, ya sea con la técnica Masquelet o con aloinjerto de segmentos diafisarios óseos. ${ }^{46}$ Mendieta y cols. estudiaron la utilidad de PRP y factores de crecimiento en defectos óseos, experiencia en el Hospital Regional «Lic. Adolfo López Mateos» del ISSSTE, en la Ciudad de México, donde se estudiaron ocho pacientes con defectos óseos, tratados quirúrgicamente, en quienes se utilizó PRP e injerto con hidroxiapatita y colágeno bovino, con un seguimiento radiográfico de $18 \mathrm{se-}$ manas posteriores a la cirugías, donde se observó que entre la semanas 10 a 14 el mayor número de pacientes mostraron consolidación ósea con resultados beneficiosos con el uso de PRP. ${ }^{47}$

\section{Columna}

EI PRP también puede utilizarse en degeneración de disco intervertebral, artritis de las facetas articulares y artritis de la articulación sacroiliaca. Hay estudios tanto in vivo como in vitro donde se ha probado la eficacia del uso de factores de crecimiento, ya que inducen la regeneración discal con resultados positivos. Expertos en medicina regenerativa han demostrado una proliferación de células del anillo fibroso después de cuatro días de estar en presencia de TGF- $\beta 1$. Hayes y cols. han revelado que la presencia de TGF- $\beta 1$ y factor de crecimiento insulínico tipo 1 (IGF-1, por sus siglas en inglés) en el anillo fibroso, estimula a sus células a sintetizar glucosaminoglicanos sulfatados y colágeno tipo I y II. La administración de IGF-1 y PDGF reduce el porcentaje de la apoptosis de las células del anillo fibroso. Chen y colaboradores mencionan que el PRP promueve la regeneración de las células del núcleo pulposo aumentando la matriz y los niveles de mARN responsable con un aumento significativo en la altura del disco. ${ }^{48}$

Muthu y equipo realizan una revisión sistemática y metaanálisis para evaluar el beneficio de la inyección intradiscal del PRP en el manejo de la enfermedad lumbar discal, donde incluyeron 12 estudios, 2 estudios aleatorizados controlados (RTC), cinco prospectivos y cinco retrospectivos, teniendo un total de 317 pacientes. En VAS y SF-36 se encontró estadísticamente significativa la mejoría, aunque se halló una heterogeneidad significativa, mientras que en la escala de índice de discapacidad de Oswestry (ODI), componente físico de SF-36 y la mejoría estructural basada en los cambios de señal en la resonancia magnética nuclear (RMN) no se observaron de forma significativa. No se encontraron efectos adversos relacionados con el procedimiento. Se necesitan futuros estudios para establecer el papel del PRP en el manejo de la enfermedad discal degenerativa, a pesar de que los resultados de los estudios analizados son prometedores, se requieren más estudios a doble ciego aleatorizados. ${ }^{48} \mathrm{La}$ Tabla 4 ilustra diferentes estudios de PRP en alteraciones del disco intervertebral.

EI PRP es el producto biológico que más se utiliza en el tratamiento de las articulaciones facetarias. Los factores de crecimiento aumentan la actividad metabólica de los fibroblastos y/o osteoblastos, reducen la apoptosis y promueven la angiogénesis, aumentando el flujo sanguíneo y la circulación al nuevo tejido formado, incrementa la expresión del gen procolágeno y factor de crecimiento derivado del colágeno, el cual incrementa la fuerza tensil del nuevo tejido. Recientemente se ha utilizado la aplicación intraósea en los pacientes que presentan edema óseo en plataformas vertebrales en niveles con disco degenerado. ${ }^{49}$

Algunos autores describen un protocolo que incluye todos los niveles donde exista aumento de líquido sinovial en las facetas o disminución de la altura del disco. El tratamiento se realiza en facetas, foráminas, ramo medial, ligamentos supra e interespinoso y aplicación intramuscular del plasma pobre en plaquetas (PPP) en multifidus. ${ }^{50}$ Todo ello guiado con una combinación de fluoroscopia y ultrasonido. ${ }^{51} \mathrm{En}$ 
Tabla 4: Diferentes estudios del uso de plasma rico en plaquetas en degeneración del disco intervertebral.

\begin{tabular}{|c|c|c|c|}
\hline Detalles de estudio & Tipo de estudio & Seguimiento & Conclusiones \\
\hline $\begin{array}{l}\text { Monfett et al, } 2016 \\
\text { Dolor lumbar discógeno, } \\
\text { degeneración del disco lumbar }\end{array}$ & Estudio prospectivo $(n=29)$ & 2 años & $\begin{array}{l}\text { Las infiltraciones intradiscales demostraron seguridad } \\
\text { continua y mejoría en el dolor y la función a los dos años } \\
\text { después del procedimiento }\end{array}$ \\
\hline $\begin{array}{l}\text { Tuakli-Wosornu et al, } 2016 \\
\text { Dolor lumbar discógeno }\end{array}$ & $\begin{array}{l}\text { Prospectivo, doble ciego, estudio } \\
\text { randomizado controlado }(n=47)\end{array}$ & 1 año & $\begin{array}{l}\text { Mejoría significativa a las ocho semanas de seguimiento, } \\
\text { con un mantenimiento de la mejoría comparado con los } \\
\text { controles al año de seguimiento }\end{array}$ \\
\hline $\begin{array}{l}\text { Navani et al, } 2018 \\
\text { Dolor discógeno lumbar }\end{array}$ & $\begin{array}{l}\text { Prospectivo, serie de casos } \\
\qquad(\mathrm{n}=20)\end{array}$ & 18 meses & $\begin{array}{l}>50 \% \text { mejoraron en VAS en } 93 \% \text { de los pacientes a los } \\
18 \text { meses. Mejoría de la SF-36 en } 93 \% \text { a los } 18 \text { meses }\end{array}$ \\
\hline $\begin{array}{l}\text { Cheng et al, } 2019 \\
\text { Discos intervertebrales } \\
\text { degenerativo sintomático }\end{array}$ & Randomizado controlado $(\mathrm{n}=29)$ & 5 a 9 años & $\begin{array}{l}21 \text { pacientes con datos disponibles para el seguimiento, } \\
\text { en } 71 \% \text { se reportó éxito significativo de mejoría tanto en } \\
\text { el dolor como la función }\end{array}$ \\
\hline
\end{tabular}

VAS = escala visual analógica (por sus siglas en inglés).

casos de canal lumbar estrecho la aplicación de PRP por vía epidural caudal brinda mejoría importante en el control del dolor. El protocolo incluye de una a tres aplicaciones cada dos a cuatro semanas dependiendo de la mejoría. ${ }^{52}$

Se debe valorar siempre las articulaciones sacroiliacas, ya que de estar sintomáticas afectan el resultado del intervencionismo espinal si no se tratan al mismo tiempo que la columna lumbar. En la articulación sacroiliaca hay una discusión extensa en la literatura en el uso y la efectividad de biológicos en el manejo del dolor alrededor de la articulación. Estos mismos principios pueden ser aplicados a las inyecciones de la articulación sacroiliaca y la infiltración de los ligamentos de la articulación sacroiliaca. ${ }^{53}$

Wu y cols. realizaron un estudio prospectivo aleatorizado comparando el PRP contra anestésico local y corticosteroides en inyección intraarticular para el tratamiento del síndrome articular facetario. Estudiaron a 46 pacientes con dicha patología, evaluándose el VAS, cuestionario de discapacidad de Roland-Morris (RMQ, por sus siglas en inglés), ODI y MacNab modificado. Se evaluaron hasta seis meses después del tratamiento y se observó que el PRP autólogo es una opción terapéutica superior por una eficacia de mayor duración que el grupo control. ${ }^{54}$

Kirchner y cols. evaluaron a 86 pacientes con dolor lumbar crónico y enfermedad degenerativa discal lumbar en un estudio retrospectivo observacional. Concluyeron que las infiltraciones intradiscales y facetarias con PRGF reducen el dolor de manera significativa y que en $91 \%$ de los pacientes presentaron un resultado excelente con un VAS de 0 a 3 en un seguimiento de hasta seis meses. ${ }^{55}$
En un estudio piloto doble ciego aleatorizado se comparó rico en leucocitos (LR-PRP) contra corticosteroides en inyección epidural caudal para el tratamiento del dolor espinal complejo crónico degenerativo, se estudiaron 50 pacientes. Se concluyó que las infiltraciones de LR-PRP en epidural caudal guiado por control fluoroscópico es superior al corticosteroide tanto en el efecto del alivio del dolor a largo plazo como en la mejoría de la calidad de vida hasta seis meses, sin complicaciones ni efectos adversos. ${ }^{56}$

Una revisión sistemática de estudios comparativos de inyecciones de PRP contra corticosteroides en espondilosis lumbar y artropatía sacroiliaca examinó cinco estudios con nivel I-III, 242 pacientes, 114 PRP y 128 corticosteroides. Concluyó que hay cierta evidencia de que la inyección con PRP es más efectiva con un seguimiento a largo plazo en comparación con la inyección de corticosteroides. ${ }^{57}$

\section{Tendinosis del supraespinoso}

La tendinopatía es una patología de alta prevalencia. Hipotéticamente se menciona que en lugar de una inflamación la causa principal de la tendinopatía crónica es el insuficiente potencial de curación. Los factores de crecimiento, citoquinas y quimiocinas modulan la inflamación y la regeneración tisular. Estudios in vitro han demostrado que el PRP puede promover la proliferación de tenocitos y facilita la reparación tendinosa. En una revisión sistemática y metaanálisis de estudios aleatorizados sobre la efectividad de las infiltraciones de PRP en la tendinopatía del manguito rotador se concluyó que a corto plazo (de tres a seis semanas) y a mediano plazo (12 semanas) la efecti- 
vidad de las infiltraciones con PRP en comparación con infiltraciones placebo, no infiltraciones o fisioterapia fue indistinguible, evaluando tanto la reducción del dolor como la mejoría funcional. A pesar de eso, la infiltración de PRP en el manguito rotador, mejora el dolor a largo plazo (> 24 semanas) en los grupos control mencionados. ${ }^{58}$

Hay estudios nivel I a favor del empleo de PRP en cuanto a mejoría del dolor y de la función, de mayor rapidez de recuperación en tendinopatías crónicas del manguito de los rotadores. ${ }^{44} \mathrm{La}$ falta de calidad en evidencia ha limitado la aceptación generalizada del PRP, BMAC y otros tratamientos llamados «ortobiológicos» para las lesiones parciales del manguito rotador y otras tendinopatías asociadas. De cualquier manera, las investigaciones recientes van a favor de las infiltraciones del PRP sobre los corticosteroides en el tratamiento conservador de la patología del manguito rotador. Se ha demostrado del efecto perjudicial de los corticosteroides en cuanto se realizan intervenciones quirúrgicas posteriormente, los cirujanos deben ser cautos con las infiltraciones con corticosteroides si existen alternativas como el PRP. Las infiltraciones con corticosteroides quizá han sido el tratamiento conservador habitual en el pasado, pero el PRP tal vez sea una herramienta más efectiva en nuestro arsenal. El coste de los tratamientos es algo que debemos valorar, poniendo en una balanza el riesgo de una reparación quirúrgica de una lesión subsecuente a una infiltración de corticosteroides contra el coste-beneficio del tratamiento con PRP. ${ }^{59}$

Hay dos estudios aleatorizados evaluando el PRP versus infiltración con solución salina y punción seca respectivamente en el tratamiento de la enfermedad del manguito rotador (tendinopatía y roturas parciales). Rha y cols. encontraron que el PRP provee más alivio sintomático y mejoría funcional desde las seis semanas a los seis meses postinfiltración. Kesiknurun y cols. no encontraron diferencia significativa entre leucocitos PRP e infiltración con solución salina en ningún punto del seguimiento hasta un año postinfiltración. ${ }^{36}$

\section{Tendinopatía patelar}

Una revisión sistemática y metaanálisis de dos estudios aleatorizados que evalúan la eficacia de L-PRP en tendinosis patelar sugiere que el PRP es estadísticamente mejor que la punción seca o la terapia de ondas de choque extracorpórea a los seis meses postratamiento. ${ }^{36}$

\section{Lesiones musculares}

Una revisión sistemática y metaanálisis de seis estudios aleatorizados evalúan la efectividad del PRP en el regreso temprano al deporte, donde el tiempo fue significativamente más corto con este tratamiento. ${ }^{36}$

\section{Aplicaciones quirúrgicas}

La mayoría de los estudios evalúan la reparación del manguito rotador y la plastia del ligamento cruzado anterior (LCA, por sus siglas en inglés). En cuanto a la plastia del manguito rotador, Jo y cols. observaron que en lesiones grandes de éste la frecuencia de rerrotura fue $20 \%$ menor añadiendo PRP. Por otro lado, en una revisión sistemática de nueve estudios aleatorizados y dos estudios cohortes se evaluó el uso de PRP en la plastia de LCA y se demostró que el uso de PRP en el injerto y en los túneles podría beneficiar en la maduración del injerto y también en el retorno al deporte. ${ }^{36}$

En lesiones de tendón de Aquiles completas se añade a la plastia término-terminal la formulación número 3 (fracción 2 activada y coagulada) y además infiltración intratendón y peritendón de PRP en su formulación número 2 (fracción 1 y 2 activadas). En las lesiones crónicas se realiza la técnica habitual término-terminal uniendo los dos cabos, dejando el tejido fibroso añadiendo PRP con la formulación 2 y 3 sin necesidad de realizar otras técnicas quirúrgicas en las cuales se tiene que utilizar un colgajo de la fascia de los gemelos como la de Christensen-Silverskjiold modificada por Enríquez y cols., entre otras. ${ }^{60}$

Trams y cols. realizaron una revisión sistemática y metaanálisis del uso clínico del PRP en alteraciones y cirugía de rodilla. Revisaron 83 estudios clínicos y encontraron que con el PRP mejoran los resultados en $\mathrm{OA}$, se aplica en el tratamiento artroscópico para la degeneración condral, tiene influencia en la curación del menisco, es más rápido el regreso al deporte después de una lesión muscular y reduce la pérdida sanguínea después de una artroplastia total de rodilla. En este estudio se confirma que hay beneficios significativos del uso de PRP en OA de rodilla comparado con varios grupos control, y que es seguro comparado con grupos control. Los autores recomiendan el uso de PRP en OA de rodilla, sugieren realizar más estudios de investigación y que sea determinado el protocolo óptimo de tratamiento (número de inyecciones, periodo). Los métodos de preparación requieren estandarización. Los estudios deben establecer el coste-beneficio del PRP en comparación con otros tratamientos. ${ }^{61}$ 


\section{Tendinopatía aquilea}

No hay beneficio clínico entre infiltraciones de PRP y solución salina placebo o ejercicios de rehabilitación. ${ }^{36}$ En las lesiones de tendón de Aquiles están las parciales y las completas y de éstas dos hay tanto agudas como crónicas. En lesiones parciales, tanto agudas como crónicas, se utilizan infiltraciones de PRP guiadas por ultrasonido a razón de una a tres sesiones cada dos semanas, dependiendo de la respuesta al tratamiento y el volumen será de acuerdo al tamaño de la lesión de 1 a $5 \mathrm{~cm}^{3}$ aproximadamente.

\section{Ligamentos de rodilla}

Zou y cols. estudiaron el efecto del PRP intraarticular en dolor refractario después de una lesión de bajo grado del ligamento colateral medial de rodilla. Evaluaron 52 pacientes que recibieron tres sesiones de PRP intraarticular de forma semanal, mejorando la prueba de IKDC uno, tres y seis meses y por estudio de imagen con RMN se observó la curación del ligamento colateral medial (LCM) a los seis meses. ${ }^{62}$

Yoshida y cols. reportan tres casos en el tratamiento de las lesiones crónicas del ligamento colateral medial con PRP. Observaron que los lesionados, por término medio, regresaron al deporte a las 10 semanas de haber iniciado las infiltraciones. También observaron que con estudio Doppler puede desaparecer la ausencia de la reducción de la señal de neovascularización en comparación con la imagen pretratamiento con PRP. Y que en el estudio con RMN realizada entre las tres y cuatro semanas de haber iniciado el tratamiento hay curación completa del LCM. ${ }^{63}$

Barastegui y cols. aplican intraligamento PRGF guiado por ultrasonido en lesiones parciales del ligamento cruzado posterior y colocan una rodillera específica para LCP, la cual aplica una fuerza anterior constante en la tibia. Todo ello ayuda a la curación del LCP con una adecuada tensión. En 13 jugadores de fútbol con lesiones parciales grado I y II del LCP los resultados fueron satisfactorios en la evaluación de Tegner, obteniendo valores de nueve en 12 pacientes y en la RMN se evidenció la curación del ligamento. Todos los pacientes regresaron al deporte. ${ }^{64}$

\section{Contraindicaciones de la administración de plasma rico en plaquetas}

Antiagregantes plaquetarios: se puede inhibir la desgranulación plaquetaria y la liberación de factores de crecimiento y de moléculas bioactivas, mermando las propiedades curativas de los preparados PRP. Estos fármacos tienen distintos mecanismos de acción como inhibidores reversibles o irreversibles de la ciclooxigenasa, inhibidores del receptor difosfato de adenosina, inhibidores de la recaptación de adenosina, inhibidores de la fosfodiesterasa e inhibidores de la glucoproteína IIB/IIIA. ${ }^{65}$

Antiinflamatorios no esteroideos (AINE): son inhibidores reversibles de la ciclooxigenasa utilizados habitualmente como antiinflamatorios y analgésicos, presentan una alteración de la agregación plaquetaria, y por tanto una disminución potencial del efecto terapéutico. ${ }^{66}$

Lidocaína y la ropivacaína: inhiben la agregación plaquetaria en respuesta a la activación mediante colágeno o difosfato de adenosina. ${ }^{67}$

\section{Conclusiones}

El plasma rico en factores de crecimiento con aproximadamente 18 años de uso en ortopedia tiene un futuro prometedor. Hoy en día ya existe suficiente evidencia científica para su utilización en diversas patologías ortopédicas ya mencionadas, sobresaliendo su utilidad en OA de rodilla, epicondilitis lateral, tendinopatía del glúteo medio y tendinopatía patelar. EI PRP tiene la versatilidad de que se puede utilizar en distintas formulaciones de acuerdo a la indicación correspondiente.

La OA es un verdadero problema de salud pública y todo un reto para el ortopedista; sin embargo, al contar con estas herramientas biológicas en nuestro arsenal, tenemos la gran ventaja de llegar directamente donde se origina el problema, es decir, al hueso subcondral, por ejemplo, en las infiltraciones intraóseas o la osteocoreplastia tanto de PRP como de BMAC o BMA. Hoy día existe suficiente evidencia científica que posiciona al PRP como el tratamiento más recomendado en el manejo del dolor en la OA de rodilla.

En cuanto a su uso en reconstrucción ósea, tendinopatía del supraespinoso, patología de columna, lesiones musculares, lesiones de ligamentos colaterales de rodilla, tendinopatía aquilea y aplicaciones quirúrgicas cada vez hay más evidencia científica de que estas terapias biológicas tienen un futuro prometedor a corto plazo.

Así pues, el PRP apunta firmemente como un potente analgésico y antiinflamatorio natural, además de tener potencial regenerador al actuar como elemento señalizador en las células mesenquimales de nuestro 
organismo en el sitio que se esté aplicando. Nos parece que ya es un hecho que debe estar dentro del arsenal de nuestra práctica diaria e ir dejando de lado el uso y sobreuso de infiltraciones con corticosteroides así como la administración de analgésicos, antiinflamatorios no esteroideos por las complicaciones que se puedan tener con su utilización tanto de forma sistémica como local. Por el momento se tiene accesibilidad a varios sistemas de preparación con sus debidas regulaciones y con ellos poder utilizarlos para beneficio de los pacientes. Aún falta quizá la estandarización de los sistemas para llegar a tener mejores resultados, con base en la calidad de cada uno de ellos así como de una dosificación determinada, estableciendo cuál será la mejor cantidad de plaquetas y de factores de crecimiento a utilizar en determinada indicación terapéutica.

\section{Referencias}

1. Khan KM, Cook JL, Bonar F, et al. Histopathology of common tendinopathies: update and implications for clinical management. Sports Med. 1999; 27 (6): 393-408.

2. Coombes BK, Bisset L, Vicenzino B. Efficacy and safety of corticosteroid injections and other injections for management of tendinopathy: a systematic review of randomised controlled trials. Lancet. 2010; 376 (9754): 1751-1767.

3. Marx RE, Carlson ER, Eichstaedt RM, Schimmele SR, Strauss JE, Georgeff KR. Platelet-rich plasma: Growth factor enhancement for bone grafts. Oral Surg Oral Med Oral Pathol Oral Radiol Endod. 1998; 85 (6): 638-646.

4. Bansal H, Leon J, Pont JL, Wilson DA, Bansal A, Agarwal D, et al. Platelet-rich plasma (PRP) in osteoarthritis (OA) knee: Correct dose critical for long term clinical efficacy. Sci Rep. 2021; 11 (1): 3971.

5. Boswell SG, Cole BJ, Sundman EA, et al. Platelet-rich plasma: a milieu of bioactive factors. Arthroscopy. 2012; 28 (3): 429439.

6. Blair P, Flaumenhaft R. Platelet alpha-granules: basic biology and clinical correlates. Blood Rev. 2009; 23 (4): 177-189.

7. Malanga GA, Goldin M. PRP: review of the current evidence for musculoskeletal conditions. Curr Phys Med Rehabil Rep. 2014; 2: 1-5.

8. Magalon J, Bausset O, Serratrice N, Giraudo L, Aboudou H, Veran J, et al. Characterization and comparison of 5 plateletrich plasma preparations in a single-donor model. Arthroscopy. 2014; 30 (5): 629-638.

9. Mautner K, Blazuk J. Where do injectable stem cell treatments apply in treatment of muscle, tendon, and ligament injuries? PM R. 2015; 7 (4 Suppl): S33-S40.

10. Anitua E, Sanchez M. A new biological approach to orthopedic surgery and sports medicine. España: Team Work Media;2013. pp. 40-52.

11. Descalzi F, Ulivi V, Cancedda R, Piscitelli F, Luongo L, Guida $F$, et al. Platelet-rich plasma exerts antinociceptive activity by a peripheral endocannabinoid-related mechanism. Tissue Eng Part A. 2013; 19 (19-20): 2120-2129.

12. Le ADK, Enweze L, DeBaun MR, Dragoo JL. Current clinical recommendations for use of platelet-rich plasma. Curr Rev Musculoskelet Med. 2018; 11: 624-634.
13. Anitua E, Sanchez M. A new biological approach to orthopedic surgery and sports medicine. España: Team Work Media;2013. pp. 55-71.

14. Li H, Hicks JJ, Wang L, Oyster N, Philippon MJ, Hurwitz S, et al. Customized platelet-rich plasma with transforming growth factor $\beta 1$ neutralization antibody to reduce fibrosis in skeletal muscle. Biomaterials. 2016; 87: 147-156.

15. Miroshnychenko O, Chang WT, Dragoo JL. The use of plateletrich and platelet-poor plasma to enhance differentiation of skeletal myoblasts: implications for the use of autologous blood products for muscle regeneration. Am J Sports Med. 2017; 45 (4): 945-953.

16. Anitua E, Sanchez M. A new biological approach to orthopedic surgery and sports medicine. España: Team Work Media; 2013. pp. 74-86.

17. Kon E, Di Matteo B, Delgado D, Cole BJ, Dorotel A, Dragoo $\mathrm{JL}$, et al. Platelet-rich plasma for the treatment of knee osteoarthristis: an expert opinión and proposal for a novel classification and coding system. Expert Opin Biol Ther. 2020; 20 (12): 1447-1460.

18. Goldring MB, Goldring SR. Articular cartilage and subchondral bone in the pathogenesis of osteoarthritis. Ann N Y Acad Sci. 2010; 1192: 230-237.

19. Suri S, Walsh DA. Osteochondral alterations in osteoarthritis. Bone. 2012; 51 (2): 204-211.

20. Mapp PI, Walsh DA. Mechanisms and targets of angiogenesis and nerve growth in osteoarthritis. Nat Rev Rheumatol. 2012; 8 (7): 390-398.

21. Imhof H, Sulzbacher I, Grampp S, Czerny C, Youssefzadeh $S$, Kainberger F. Subchondral bone and cartilage disease: a rediscovered functional unit. Invest Radiol. 2000; 35 (10):581-588.

22. Malinin T, Ouellette EA. Articular cartilage nutrition is mediated by subchondral bone: a long-term autograft study in baboons. Osteoarthritis Cartilage. 2000; 8 (6): 483-491.

23. Aaron RK, Racine J, Dyke JP. Contribution of circulatory disturbances in subchondral bone to the pathophysiology of osteoarthritis. Curr Rheumatol Rep. 2017; 19 (8): 49.

24. Moussa M, Lajeunesse D, Hilal G, El Atat O, Haykal G, Serhal $\mathrm{R}$, et al. Platelet rich plasma (PRP) induces chondroprotection via increasing autophagy, anti-inflammatory markers, and decreasing apoptosis in human osteoarthritic cartilage. Exp Cell Res. 2017; 352 (1): 146-156.

25. Milano G, Sánchez M, Jo CH, Saccomanno M, Thampatty BP, Wang JHC. Platelet-rich plasma in orthopaedic sports medicine: state of art. JISAKOS. 2019; 4: 188-195.

26. Delgado D, Garate A, Vincent H, Bilbao AM, Patel R, Fiz N, et al. Current concepts in intraosseous Platelet-Rich Plasma injections for knee osteoarthritis. J Clin Orthop Trauma. 2019; 10 (1): 36-41.

27. Montañez-Heredia E, Irízar S, Huertas PJ, Otero E, Del Valle $\mathrm{M}$, Prat I, et al. Intra-articular injections of platelet-rich plasma versus hyaluronic acid in the treatment of osteoarthritic knee pain: a randomized clinical trial in the context of the Spanish national health care system. Int J Mol Sci. 2016; 17 (7): 1064.

28. Wang-Saegusa A, Cugat R, Ares O, Seijas R, Cuscó X, Garcia-Balletbó M. Infiltration of plasma rich in growth factors for osteoarthritis of the knee short-term effects on function and quality of life. Arch Orthop Trauma Surg. 2011; 131 (3): 311-317.

29. Sánchez M, Fiz N, Guadilla J, Padilla S, Anitua E, Sánchez $P$, et al. Intraosseous infiltration of platelet-rich plasma for severe knee osteoarthritis. Arthrosc Tech. 2014; 3 (6): e713-e717. 
30. Cugat R, Alentorn-Geli E, Navarro J, Cuscó X, Steinbacher $G$, Seijas R, et al. A novel autologous-made matrix using hyaline cartilage chips and platelet-rich growth factors for the treatment of full-thickness cartilage or osteochondral defects: preliminary results. J Orthop Surg (Hong Kong). 2020; 28 (1): 2309499019887547.

31. Cugat R, Alentorn-Geli E, Steinbacher G, Álvarez-Díaz P, Cuscó X, Seijas R, et al. Treatment of knee osteochondral lesions using a novel clot of autologous plasma rich in growth factors mixed with healthy hyaline cartilage chips and intraarticular injection of PRGF. Case Rep Orthop. 2017; 2017: 8284548.

32. Ip HL, Nath DK, Sawleh SH, Kabir MH, Jahan N. Regenerative medicine for knee osteoarthritis - the efficacy and safety of intra-articular platelet-rich plasma and mesenchymal stem cells injections: a literature review. Cureus. 2020; 12 (9): e10575.

33. Dwyer T, Chahal J. Editorial commentary: injections for knee osteoarthritis: Doc, You Gotta Help Me! Arthroscopy. 2021; 37 (4): $1288-1289$.

34. Lana JFSD, da Fonseca LF, Macedo RDR, Mosaner T, Murrell $\mathrm{W}$, Kumar A, et al. Platelet-rich plasma vs bone marrow aspirate concentrate: An overview of mechanisms of action and orthobiologic synergistic effects. World J Stem Cells. 2021; 13 (2): 155-167.

35. Dallo I, Rivarola HF, Collazo C, Chahla J, Gobbi A. Terapias biológicas en artroscopia de rodilla. De las ciencias básicas a la aplicación clínica. Artroscopia. 2020; 27 (2): 1-4.

36. Collins T, Dinesh A, Barkatali B. Plasma-rich plasma: a narrative review. EFORT Open Rev. 2021; 6: 225-235.

37. Estrada E, Décima JL, Rodríguez M, Di Tomaso M, Roberti J. Patient-reported outcomes after platelet-rich plasma, bone marrow aspirate, and adipose-derived mesenchymal stem cell injections for symptomatic knee osteoarthritis. Clin Med Insights Arthritis Musculoskelet Disord. 2020; 13: 1179544120931086.

38. Szwedowski D, Dallo I, Irlandini E, Gobbi A. Osteo-core Plasty: a minimally invasive approach for subchondral bone marrow lesions of the knee. Arthrosc Tech. 2020; 9(11): e1773-e1777.

39. Raeissadat SA, Ghazi Hosseini P, Bahrami MH, Salman Roghani R, Fathi M, Gharooee Ahangar A. The comparison effects of intra-articular injection of platelet rich plasma (PRP), plasma rich in growth factor (PRGF), hyaluronic acid (HA), and ozone in knee osteoarthritis; a one year randomized clinical trial. BMC Musculoskelet Disord. 2021; 22 (1): 134.

40. Cuéllar RCT, Santos DD, Colunga FJL, Pérez ZM, Bravo AT, Zuáznabar VMC, et al. Utilidad de la ozonoterapia intraarticular en la osteoartrosis de rodilla asociada a sinovitis. Rev Cub de Med Fis y Rehab. 2012; 4 (2).

41. Sconza C, Respizzi S, Virelli L, Vandenbulcke F, lacono F, Kon E, et al. Oxygen-ozone therapy for the treatment of knee osteoarthritis: a systematic review of randomized controlled trials. Arthroscopy. 2020; 36 (1): 277-286.

42. Mishra AK, Skrepnik NV, Edwards SG, Jones GL, Sampson $S$, Vermillion DA, et al. Efficacy of platelet-rich plasma for chronic tennis elbow: a double-blind, prospective, multicenter, randomized controlled trial of 230 patients. Am J Sports Med. 2014; 42 (2): 463-471.

43. Miller LE, Parrish WR, Roides B, Bhattacharyya S. Efficacy of platelet-rich plasma injections for symptomatic tendinopathy: systematic review and meta-analysis of randomised injectioncontrolled trials. BMJ Open Sport Exerc Med. 2017; 3 (1): e000237.

44. Fernández-Fairen M, Gutiérrez-Gómez J, Hernández-Vaquero D, Torres-Pérez Al, Sueiro-Fernández J. Evidencia científica de los factores de crecimiento en cirugía ortopédica y traumatología. Ortho-tips. 2014; 10 (4): 235-257.

45. Fitzpatrick J, Bulsara MK, O'Donnell J, Zheng MH. Leucocyterich platelet-rich plasma treatment of gluteus medius and minimus tendinopathy: a double-blind randomized controlled trial with 2-year follow-up. Am J Sports Med. 2019; 47 (5): 1130-1137.

46. Masquelet A, Kanakaris NK, Obert L, Stafford P, Giannoudis PV. Bone repair using the Masquelet technique. J Bone Joint Surg Am. 2019; 101 (11): 1024-1036.

47. Mendieta ATR, Alvarado SJC, Negrete CJ. Utilidad del plasma rico en plaquetas y factores de crecimiento en defectos óseos, experiencia en el Hospital Regional Lic. Adolfo López Mateos del ISSSTE. Acta Ortop Mex. 2007; 21 (5): 256-260.

48. Muthu S, Jeyaraman M, Chellamuthu G, Jeyaraman N, Jain $R$, Khanna M. Does the intradiscal injection of platelet rich plasma have any beneficial role in the management of lumbar disc disease? Global Spine J. 2021; 2192568221998367.

49. Kirchner F, Pinar A, Milani I, Prado R, Padilla S, Anitua E. Vertebral intraosseous plasma rich in growth factor (PRGFEndoret) infiltrations as a novel strategy for the treatment of degenerative lesions of endplate in lumbar pathology: description of technique and case presentation. J Orthop Surg Res. 2020; 15 (1): 72.

50. Desai MJ, Mansfield JT, Robinson DM, Miller BC, Borg-Stein $\mathrm{J}$. Regenerative medicine for axial and radicular spine-related pain: a narrative review. Pain Pract. 2020; 20 (4): 437-453.

51. Ye L, Wen C, Liu H. Ultrasound-guided versus low dose computed tomography scanning guidance for lumbar facet joint injections: same accuracy and efficiency. BMC Anesthesiol. 2018; 18 (1): 160

52. Aufiero D, Vincent $H$, Sampson S, Bodor M. Regenerative injection treatment in the spine: review and case series with platelet rich plasma. J Stem Cells Res, Rev \& Rep. 2015; 2 (1): 1019.

53. Navani A, Manchikanti L, Albers SL, Latchaw RE, Sanapati $J$, Kaye AD, et al. Responsible, safe, and effective use of biologics in the management of low back pain: American Society of Interventional Pain Physicians (ASIPP) guidelines. Pain Physician. 2019; 22 (1S): S1-S74.

54. Wu J, Zhou J, Liu C, Zhang J, Xiong W, Lv Y, et al. A Prospective study comparing platelet-rich plasma and local anesthetic (LA)/corticosteroid in intra-articular injection for the treatment of lumbar facet joint syndrome. Pain Pract. 2017; 17 (7): 914-924

55. Kirchner F, Anitua E. Intradiscal and intra-articular facet infiltrations with plasma rich in growth factors reduce pain in patients with chronic low back pain. J Craniovertebr Junction Spine. 2016; 7 (4): 250-256.

56. Ruiz-Lopez R, Tsai YC. A Randomized double-blind controlled pilot study comparing leucocyte-rich platelet-rich plasma and corticosteroid in caudal epidural injection for complex chronic degenerative spinal pain. Pain Pract. 2020; 20 (6): 639-646.

57. Ling JF, Wininger AE, Hirase T. Platelet-rich plasma versus corticosteroid injection for lumbar spondylosis and sacroiliac arthropathy: a systematic review of comparative studies. Cureus. 2021; 13 (3): e14062.

58. Lin MT, Wei KC, Wu CH. Effectiveness of platelet-rich plasma injection in rotator cuff tendinopathy: a systematic review and meta-analysis of randomized controlled trials. Diagnostics (Basel). 2020; 10 (4): 189.

59. Sheean AJ. Editorial commentary: platelet-rich plasma has advantages over corticosteroid for nonoperative treatment 
of rotator cuff pathology: another step in the right direction. Arthroscopy. 2021; 37 (2): 518-520.

60. Enríquez JA, García A, Pastrana F, López Valero A, González A, Romo FJ. Tratamiento de las rupturas crónicas del Tendón de Aquiles con plastia de Christensen-Silverskjiold utilizando tejido fibroso como puente. Rev Mex Ortop Trauma. 2002; 16 (3): 119-123.

61. Trams E, Kulinski K, Kozar-Kaminska K, Pomianowski S, Kaminski R. The clinical use of platelet-rich plasma in knee disorders and surgery-a systematic review and meta-analysis. Life (Basel). 2020; 10 (6): 94.

62. Zou G, Zheng M, Chen W, He X, Cang D. Autologous platelet-rich plasma therapy for refractory pain after low-grade medial collateral ligament injury. J Int Med Res. 2020; 48 (2): 300060520903636

63. Yoshida M, Marumo K. An autologous leukocyte-reduced platelet-rich plasma therapy for chronic injury of the medial collateral ligament in the knee: a report of 3 successful cases. Clin J Sport Med. 2019; 29 (1): e4-e6.

64. Barastegui D, Alentorn-Geli E, Gotecha D, Rius M, Navarro J, Cuscó $X$, et al. Treatment of partial posterior cruciate ligament injuries with platelet-rich plasma in growth factors (PRGF) intraligamentous infiltration and a specific knee brace. Surg $\mathrm{J}$ (N Y). 2021; 7 (1): e30-e34.

65. Varon D, Spectre G. Antiplatelet agents. Hematology Am Soc Hematol Educ Program. 2009, 267-272.

66. Schippinger G, Prüller F, Divjak M, Mahla E, Fankhauser F, Rackemann S, et al. Autologous platelet-rich plasma preparations: influence of nonsteroidal anti-inflammatory drugs on platelet function. Orthop J Sports Med. 2015; 3 (6): 2325967115588896.

67. Bausset O, Magalon J, Giraudo L, Louis ML, Serratrice N, Frere $\mathrm{C}$, et al. Impact of local anaesthetics and needle calibres used for painless PRP injections on platelet functionality. Muscles Ligaments Tendons J. 2014; 4 (1): 18-23.

\section{Conflicto de intereses}

No hay conflicto de intereses. 